\title{
Capsule Commentary on Jenssen et al., Using Digital Technology to Engage and Communicate with Patients: A Survey of Patient Attitudes
}

\author{
Steven Ludwin, MD and S. Ryan Greysen, MD, MHS, MA \\ Division of Hospital Medicine, University of California, San Francisco, CA, USA.
}

J Gen Intern Med 31(1):107

DOI: $10.1007 / \mathrm{s} 11606-015-3530-0$

(c) Society of General Internal Medicine 2015

$\mathrm{T}$ his study by Jennsen et al. ${ }^{1}$ explored patient digital health preferences. The investigators looked at two healthrelated activities (peer coaching and acquisition of test results) and the desirability of receiving information through three different variants of digital technology (e-mail, text messaging, and social media), finding that patients preferred communication through more traditional means: phone more than e-mail, e-mail more than text, text more than social media. A majority of survey participants used Facebook $(58 \%)$ or text messaging $(64 \%)$, but few wanted to communicate health goals (FB 3\%, text 13\%) or test results (FB 1\%, text $13 \%$ ) through these mechanisms. Does this dampen enthusiasm for digital health adoption? Not necessarily. The preference for phone and e-mail communication may reflect privacy and secure messaging priorities.

This study did not look at patient portals. While the data on patient portals is limited, it could offer a way forward for meeting patient needs. ${ }^{2}$ Healthcare in the United States is increasingly trending towards population health management, with an emphasis on additional touchpoints beyond traditional office visits. ${ }^{3}$ This, coupled with an increasing number of patients with digital devices, makes further adoption of digital health likely in a wide range of care settings; for example, two in three patients in our hospital have brought a mobile device with them, and most have used it during their stay for healthcare-related tasks. ${ }^{4}$

In addition to studying communication preference, the investigators looked at social media for peer coaching or general health messaging. While the majority of those surveyed did not want either peer coaching or general health messaging, the investigators do point out significant trends towards participation among those that were younger, uninsured, or a racial/ ethnic minority. This could represent a tremendous opportunity for engagement in healthcare and coaching with typically underserved populations.

Do patients want digital health? How do they want it? When do they want it? And for what things? These are fundamental questions that are unlikely to be answered in a single study, but more studies like this can provide a pathway for policy and health systems leaders to tread.

Corresponding Author: Steven Ludwin, MD; Division of Hospital MedicineUniversity of California, San Francisco, CA, USA (e-mail: steven.ludwin@ucsf.edu).

\section{Compliance with Ethical Standards:}

Conflict of Interest: The author has no conflicts of interest with this article.

\section{REFERENCES}

1. Jennsen BP, Mitra N, Shah A, Wan F, Grande D. Using digital technology to engage and communicate with patients: a survey of patient attitudes. J Gen Intern Med. 2015. doi:10.1007/s11606-015-3517-x.

2. Kruse CS, Bolton K, Freriks G. The effect of patient portals on quality outcomes and its implications to meaningful use: a systematic review. J Med Internet Res. 2015;17(2):e44.

3. Ricciardi L, Mostashari F, Murphy J, Daniel JG, Siminerio EP. A national action plan to support consumer engagement via e-health. Health Aff (Millwood). 2013;32(2):376-84.

4. Ludwin S, Greysen SR. Use of smartphones and mobile devices in hospitalized patients: untapped opportunities for inpatient engagement. J Hosp Med. 2015; 10(7):459-61. 